\title{
Cutaneous Pili Migrans: A Case Report
}

\author{
Kawina Ingkapairoj Daranporn Triwongwaranat Sukhum Jiamton \\ Supenya Varothai \\ Department of Dermatology, Faculty of Medicine Siriraj Hospital, Mahidol University, Bangkok, Thailand
}

\section{Established Facts}

- Cutaneous pili migrans (CPM) is a fragment of hair penetrating into the superficial layer of the skin.

\section{Novel Insights}

- We present the first case of CPM in Thailand, which had an interesting clinical presentation.

- $\mathrm{CPM}$ is benign and usually not recurrent.

\section{Keywords}

Burrowing hair · Creeping hair · Cutaneous pili migrans .

Embedded hair

\section{Abstract}

Hair-induced creeping eruption is a rare condition characterized by a fragment of hair embedded in the superficial layer of the skin. Mainly cases from Asia are reported. We report a 39-year-old Thai female who experienced painful blackish linear eruption on the right side of the neck. The proximal end of the lesion was excised, and the rest of it was removed using forceps. The lesion suddenly disappeared. The black line that was removed from the lesion appeared to be hair. In conclusion, this condition is important and should be considered when patients present with creeping eruption. (c) 2019 S. Karger AG, Basel

E-Mail karger@karger.com

www.karger.com/sad

\section{Introduction}

Hair-induced creeping eruption is a rare condition in which a fragment of hair is embedded in the superficial layer of the skin and in the dermis as well. It can clinically present as a black line forming an eruption resembling larva migrans, which is recognized as embedded hair, burrowing hair, and creeping hair. It is important to make a differential diagnosis with creeping eruption. The first case was described by Yaffee [1] in 1957, and a total of thirty-seven cases have been reported. Locations involved included the toe, sole, ankle, breast, cheek, neck, and abdomen [1,3-6]. Currently, the etiology remains unknown.

\section{Case Presentation}

A 39-year-old Thai female patient visited the Dermatology Clinic at the Department of Dermatology, Siriraj Hospital, with a painful, blackish, thread-like structure on the right side of her neck for 1 week. She denied a history of trauma. Physical examination showed a linear 
Fig. 1. a Lateral aspect of the neck showing linear eruption with slightly raised erythema. b The blackish line was simply pulled off by a shallow incision on the skin. c Two weeks after removal of the hair, the inflammation was diminished. d Tissue from punch biopsy.

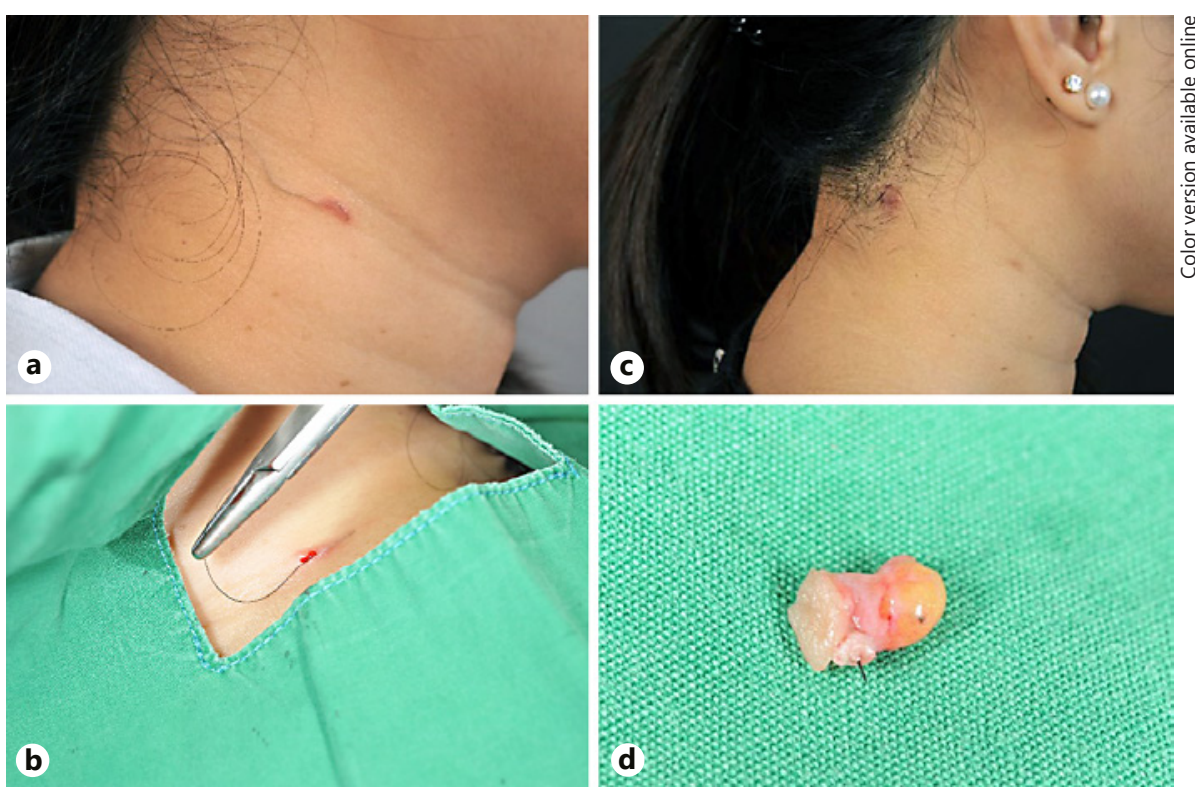

Fig. 2. Histopathology finding showing compact keratin material in the epidermis.

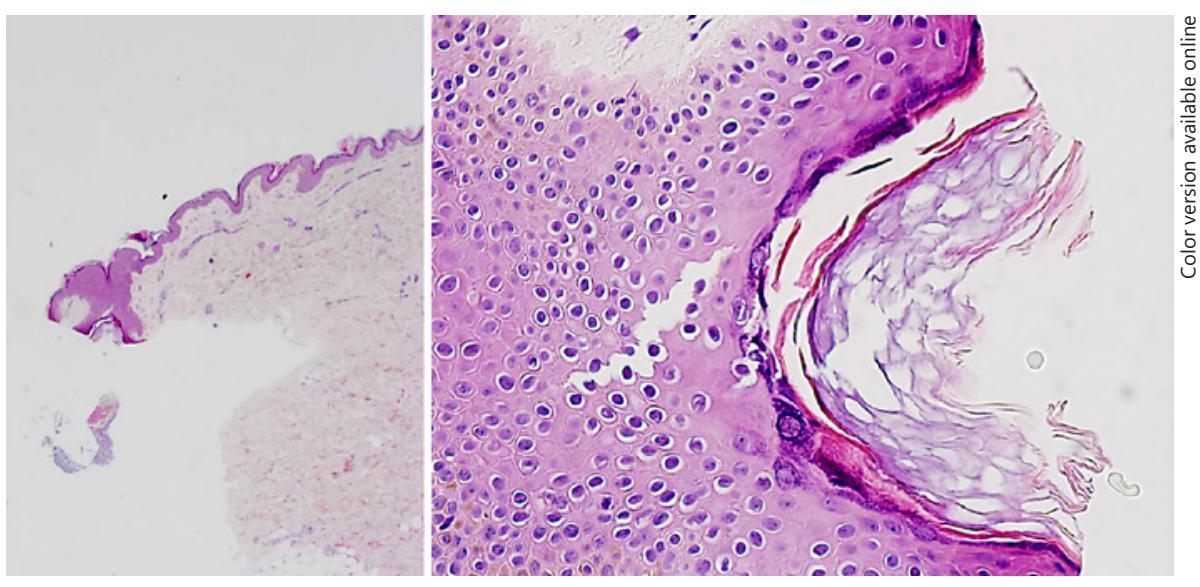

eruption with signs of inflammation surrounding the lesion (Fig. 1a). We performed a 3-mm punch biopsy at the proximal end of the lesion. The blackish line was simply extracted by forceps (Fig. 1b). The black line appeared to be a hair shaft without hair follicle. Histopathological examination revealed compact keratin material in the epidermis (Fig. 2). After the hair fragment had been removed, the lesion disappeared. At follow-up 4 weeks after treatment, the lesion was gone, and there were no signs of recurrence.

\section{Discussion}

The term "cutaneous pili migrans" (CPM) is used to describe a fragment of hair embedded in the epidermis and dermis layers of the skin. It usually presents with a blackish, linear-like eruption mimicking creeping eruption. It is a rare condition first described by Yaffee [1] in 1957. Most of the cases are from Asia.

Cutaneous Pili Migrans
There are reports stating that the common prevalence of this disease is amongst the young and middle-aged population. However, there are various studies documenting patients aged between 6 months and 58 years. Locations involved include the toe, sole, ankle, breast, cheek, neck, and abdomen [1,3-6]. Although the current understanding of $\mathrm{CPM}$ remains unclear, our case report illustrates that the pathogenesis of this condition may be acquired because no hair follicles have been reported before. Some reported cases postulated that the predisposing factor was friction between sharp hair tips and the moving body part because locations involved are friction sites. Moreover, soaked skin softens and breaks down the skin barrier [3, 5]. Franbourg et al. [2] reported the influence of ethnicity on hair structure. Asian hair has a greater diameter and tensile strength compared with Caucasian and African hair, which may be the reason why most cases were reported from Asia. Ara-

Skin Appendage Disord 2020;6:52-54 
kawa et al. [6] used dermatoscopy to identify CPM. A fine, very superficial, movable black line suspected to be hair may be characteristic of CPM in dermatoscopy.

CPM and creeping eruption are often misdiagnosed. $\mathrm{CPM}$ can move in only one direction and may be asymptomatic or painful, whereas cutaneous larva migrans can move in any direction and is extremely itchy [5].

\section{Conclusion}

Herein, we report the first case of CPM in Thailand. $\mathrm{CPM}$ is a rare and interesting condition. It must be differentiated from cutaneous larva migrans. When creeping eruptions are observed, a close-up examination is needed.

\section{Statement of Ethics}

The authors have no ethical conflicts to disclose. The patient gave her written consent to publish the details of her case.

\section{Disclosure Statement}

The authors declare that they have no conflicts of interest to disclose.

\section{References}

1 Yaffee HS. Imbedded hair resembling larva migrans. AMA Arch Derm. 1957 Aug;76(2): 254 .

2 Franbourg A, Hallegot P, Baltenneck F, Toutain C, Leroy F. Current research on ethnic hair. J Am Acad Dermatol. 2003 Jun;48(6 Suppl):S115-9.
3 Luo DQ, Liu JH, Huang YB, He DY, Zhang HY. Cutaneous pili migrans: a case report and review of the literature. Int J Dermatol. 2009 Sep;48(9):947-50.

4 Jang YH, Kim MJ, Kim SL, Chi SG, Lee WJ, Lee SJ, et al. Creeping hair in the beard area. Ann Dermatol. 2015 Oct;27(5):635-6.
5 Ishida Y, Matsubara K, Takai M, Horiguchi Y, Yoshikawa Y. A case of; creeping hair' resembling cutaneous larva migrans. Clin Exp Dermatol. 2009 Mar;34(2):256-7.

6 Arakawa Y, Nakai N, Hanada K, Katoh N. Dermatoscopy for diagnosis of creeping hair: A case repot and mini-review of the literature. Acta Derm Venereol.DOI: 10.2340/000155551124. 